\title{
Artroskopsko liječenje oštećenja tetive subskapularisa
}

\section{Arthroscopic repair of subscapularis tendon tears}

\author{
Nikola Matejčićc ${ }^{1 *}$, Andrica Lekić ${ }^{2}$
}

${ }^{1}$ Klinika za ortopediju i traumatologiju Lovran

${ }^{2}$ Fakultet zdravstvenih studija, Sveučilište u Rijeci, Rijeka

"Dopisni autor:

Nikola Matejčić, dr. med.

Klinika za ortopediju i traumatologiju Lovran Maršala Tita 1, 51415 Lovran

E-mail:mat2lovran@yahoo.com
Sažetak. Cilj: prezentacija principa, tehnike i rezultata artroskopskog liječenja oštećene tetive subskapularisa. Ispitanici i metode: u razdoblju od 1. siječnja 2015. do 1. siječnja 2019. učinili smo 289 operacija ramena zbog oštećenja tetiva rotatorne manžete. Lezije tetive subskapularisa podijelili smo po Lafosseu i liječili artroskopski ili artroskopski asistirano. Analizirali smo rezultate isključivo artroskopskog liječenja 31 dostupnog pacijenta s lezijom tetive subskapularisa kojima je od operacije do procjene prošlo 6 i više mjeseci. Pacijenti su ispitani o prije i poslijeoperacijskim mogućnostima i tegobama po upitnicima Oxford shoulder score (OSS) i Subjective shoulder value (SSV). Rezultati: kod 89 slučajeva (30,79 \%) našli smo oštećenje tetive subkapularisa od kojih 8 izoliranih (2,76 \% svih lezija manžete) i 81 udružen s oštećenjem ostalih tetiva manžete. Kod 72 pacijenta $(80,9 \%)$ učinili smo artroskopsku operaciju, a u 17 slučajeva otvorenu uz artroskopsku asistenciju. 31 dostupan pacijent iz grupe artroskopski operiranih procijenjen je 17,96 $\pm 8,25$ mjeseci od operacije upitnicima Oxford shoulder score i Subjective shoulder value (odziv 43,05\%). Oxford shoulder score značajno se povećao $s 14,19$ preoperativno na 36,74 postoperativno $(p=0,002)$. Subjective shoulder value također se značajno povećao s 27,32 na 82,33 ( $p \ll 0,001)$. Zaključak: artroskopsko liječenje oštećenja tetive subskapularisa, izolirano ili udruženo $s$ ostalim lezijama manžete, predstavlja siguran i efikasan način liječenja s odličnim rezultatima.

Ključne riječi: artroskopija; liječenje; rame; subskapularis; tetiva

Abstract. Aim: presentation of principles, techniques and results of arthroscopic subscapularis tendon repairs. Patients and methods: In the period from $1^{\text {st }}$ January 2015 until $1^{\text {st }}$ January 2019 we performed 289 rotator cuff repair surgeries. The subscapularis tendon lesions were found, and sorted according to Lafosse classification and operated arthroscopically or arthroscopically assisted. After a minimum of 6 months after surgery we assessed and analysed the results of all arthroscopic treatments of 31 available patients with a subscapularis tendon lesion. The patients were examined for preoperative and postoperative capabilities and difficulties according to the Oxford shoulder score and Subjective shoulder value questionnaires. Results: In 89 cases (30.79\%) we found subscapularis tendon tears from which 8 isolated ( $2.76 \%$ of all cuff tears) and 81 combined with other rotator cuff tears. In 72 cases $(80.9 \%)$ we performed all arthroscopic repair and in 17 cases (19.1\%) an open surgery with or without arthroscopic assistance. From all arthroscopic groups of patients, 31 of them were evaluated $17.96 \pm 8.25$ months postoperatively with patient-based Oxford shoulder score and Subjective shoulder value (response rate $43.05 \%$ ). Oxford shoulder score improved significantly from 14.19 preoperatively to 36.74 postoperatively $(p=0.002)$. Subjective shoulder value also increased significantly from 27.32 to $82.33(p<<0.001)$. Conclusion: Arthroscopic repair of a subscapularis tendon tear, isolated or combined with other rotator cuff tears, represents a safe and effective a surgical method with an excellent outcome.

Key words: arthroscopy; repair; shoulder; subscapularis; tendon 


\section{UVOD}

Subskapularis (SSC) je najveći i najjači mišić rotatorne manžete koji čini $50 \%$ njezine ukupne snage te je njegov integritet ključan za funkciju i stabilnost ramena ${ }^{1}$. Njegova tetiva sama čini prednji dio rotatorne manžete te njeno oštećenje može uzrokovati značajnu kliničku simptomatologiju. Unatoč tome kroz povijest je veći značaj u literaturi pridavan ostalim tetivama manžete, naročito supraspinatusu (SSP) i infraspinatusu (ISP), dok su lezije SSC-a smatrane rijetkim i manje važnim. Lezije rotatorne manžete, uključujući i izoliranu rupturu tetive SSC-a na kadaveričnim primjercima, prvi u literaturi opisuje John Gregory Smith 1834., potom Codman 1934. i McLaughlin 1944. i 1960., dok je prva rekonstrukcija izolirane lezije SSC-a dokumentirana 1954. godine ${ }^{2-6}$. Fokus na SSC vraćaju Gerber i Krushell 1991. objavom rezultata serije otvorenih rekonstrukcija ${ }^{7}$. Razvojem medicinske spoznaje, naročito na polju biomehanike, dijagnostike i artroskopske kirurgije, dokazan je njegov značaj i prava učestalost oštećenja, a SSC romantično nazvan "zaboravljenom tetivom" ${ }^{\prime \prime}$. Prvu artroskopsku rekonstrukciju objavljuje Burkhart 2002. godine ${ }^{9}$. Polazište SSC-a je prostrana fossa subscapularis skapule, a hvatište tuberculum minus humerusa. Gornje 2/3 hvatišta je tetivno, dok je u donjoj trećini mišićno. Ono je oblika zareza, visine oko 39,5 $\mathrm{mm}$ (tetivni dio oko $25 \mathrm{~mm}$ ), a širine oko 16 $\mathrm{mm}^{10}$. Inerviraju ga $\mathrm{nn}$. subscapularis superior et inferior i $n$. axillaris ${ }^{11}$. Interferirajuće tetivne niti SSC-a i SSP-a pri hvatištu, kao i lig coracohumerale i lig glenohumerale superior, čine stabilizirajući ("pulley") sustav tetive caput longum $m$ biceps brachii (CLMBB) na ulazu u sulcus intertubercularis humerusa ${ }^{12}$. Osnovna funkcija SSC-a je aktivna stabilizacija ramena balansom sila kontrakcije $s$ antagonističkim ISP-om i teres minorom (TM) koji se nalaze sa stražnje strane ramena. To je osnovni mehanizam koji stabilizira glavu humerusa prema centru glenoida i omogućuje deltoidnom mišiću elevaciju ruke ${ }^{13-15}$. U slučaju disrupcije navedenog mehanizma aktivne stabilizacije kod masivnih lezija manžete, dolazi do razvoja artropatije ramenog zgloba praćene kranijalizacijom glave humerusa, koju u slučaju većeg oštećenja SSC-a može pratiti i prednja subluksacija ${ }^{16-18}$. Osim ak- tivne, SSC tonusom mišića pridonosi i pasivnoj prednjoj stabilizaciji ramenog zgloba, te uz njegovu izoliranu leziju može doći do prednjeg instabiliteta. Djeluje kao unutarnji rotator humerusa, a elevaciji pridonosi više od SSP-a i ISP-a ${ }^{19}$. Artroskopija ramena ukazala je na znatno učestaliju pojavnost lezija tetive SSC-a nego što se činilo u eri otvorene kirurgije, te je omogućila točno determiniranje razmjera oštećenja. Znatno češće in susrećemo u kombinaciji s oštećenjem ostalih tetiva u sklopu tzv. anterosuperiornih lezija koje

Već i male lezije tetive subskapularisa, s obzirom na biomehanički značaj, izazivaju značajne poteškoće. Artroskopska rekonstrukcija je zbog blizine neurovaskularnih struktura vrlo izazovna i zahtjevna kirurgija koja adekvatnom pripremom i savladavanjem krivulje učenja pruža značajno bolje mogućnosti od otvorene kirurgije i daje izvrsne rezultate uz rijetke komplikacije.

uključuju i tetivu SSP-a ili masivnih lezija rotatorne manžete koje uključuju ISP i TM ${ }^{20}$. Takve lezije najčešće su degenerativne prirode uz brojne ekstrinzičke i intrinzičke faktore koji pridonose njihovu razvoju, a nalazimo ih u 27,4 - $59 \%$ artroskopskih rekonstrukcija rotatorne manže$t^{21-27}$. Izolirane lezije SSC-a znatno su rjeđe, nalazimo ih u $3-5,3 \%$ artroskopskih rekonstrukcija rotatorne manžete. Uglavnom su traumatske, nalazimo ih u mlađoj i aktivnijoj populaciji, te kod prednje luksacije ramena starijih ljudi. Mehanizam ozljede koji dovodi do rupture SSC-a je forsirana vanjska rotacija ruke uz otpor ili ekstenzija ruke koja se nalazi u abdukcijij ${ }^{27-32}$. U kliničkoj slici dominira prednja i anterolateralna bolnost, ograničenje aktivne, a uz razvoj kontrakture i pasivne pokretljivosti ramena, znaci instabiliteta i ozljede CLMBB-a, te u slučaju potpune rupture i povećan pasivni opseg vanjske rotacije ozlijeđenog ramena. Pozitivni su specifični testovi slabosti SSC-a: belly press, bear hug i lift off33-35 (slika 1, slika 2, slika 3).

Osim kliničkog pregleda, od dijagnostičkih metoda koristimo rendgenološku obradu, ultrazvuk čija je prednost što omogućuje dinamičku pretragu, MR i CT bez ili s artrografijom te obaveznom procjenom masne degeracije mišića rotatorne manžete (Fuchs, Goutallier) ${ }^{36,37}$. Liječenje može 


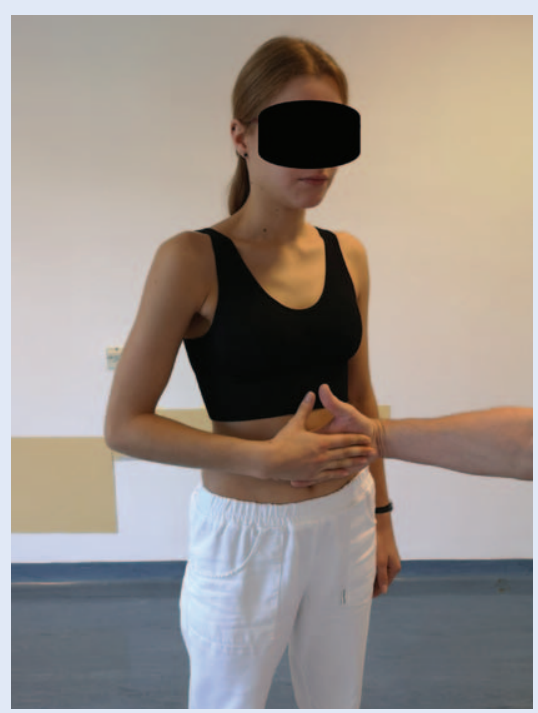

Slika 1. Belly press test: pacijent pritišće dlanom svoj trbuh s laktom u frontalnoj ravnini. Ispitivač svojim dlanom može objektivizirati snagu pritiska.

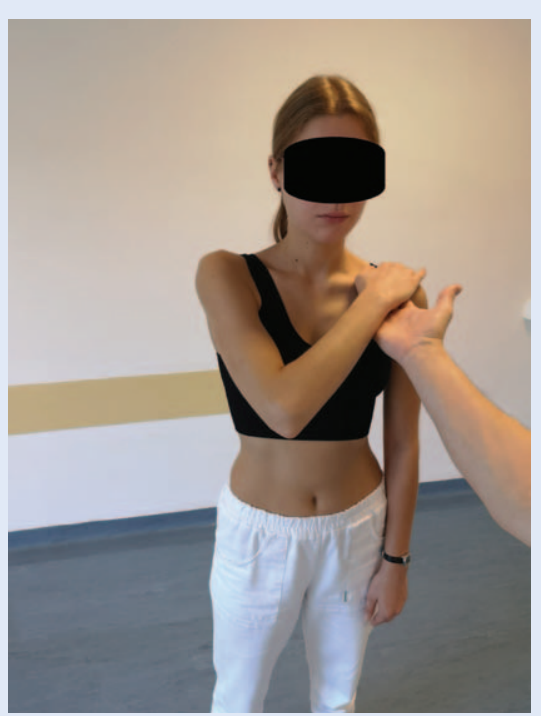

Slika 2. Bear hug test: pacijent drži dlan na svom suprotnom ramenu s laktom usmjerenim naprijed. Ispitivač diže dlan s ramena dok se pacijent tome opire.

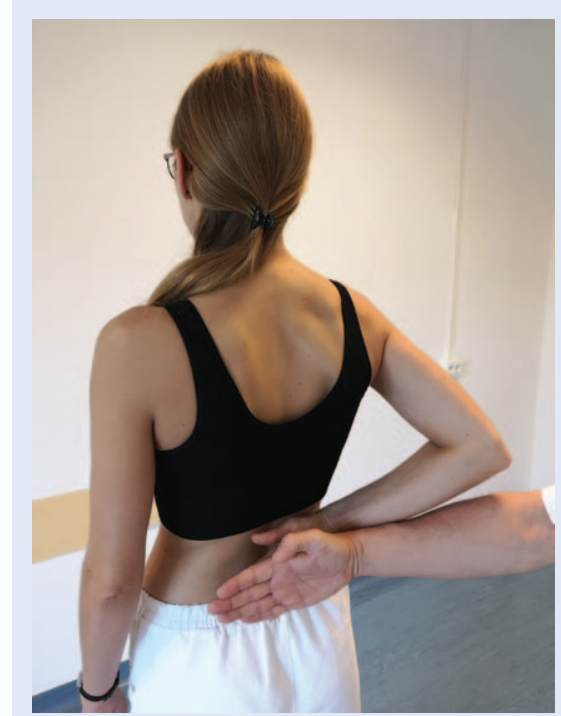

Slika 3. Lift off test: pacijent stavi svoj dlan na lumbosakralnu kralježnicu te je pokuša odvojiti od leđa bez ekstenzije lakta. Ispitivač može procijeniti snagu svojim dlanom.

Tablica 1. Artroskopska klasifikacija lezija tetive SSC po Lafosseu

\begin{tabular}{|c|l|}
\hline Tip lezije & \multicolumn{1}{c|}{ Lezija } \\
\hline 1 & Parcijalna lezija gornje trećine tetive subskapularisa \\
\hline 2 & Potpuna lezija gornje trećine tetive subskapularisa \\
\hline 3 & Potpuna lezija gornje $2 / 3$ tetive subskapularisa \\
\hline 4 & Potpuna lezija cijele tetive s centriranom glavom humerusa i masnom degeneracijom mišića $\leq 3$ \\
\hline 5 & $\begin{array}{l}\text { Potpuna lezija cijele tetive sa subluksiranom glavom humerusa, korakoidnim konfliktom i masnom } \\
\text { degeneracijom mišića } \geq 3\end{array}$ \\
\hline
\end{tabular}

biti konzervativno ili kirurško. Što je osoba mlađa i aktivnija, ruptura veća, etiologija traumatska, a degenerativne promjene manje izražene, brže ćemo se odlučiti za kirurško liječenje, dok ćemo se u suprotnom primarno prikloniti pokušaju konzervativnog liječenja fizikalnom terapijom i rehabilitacijom. Kirurško liječenje rupture SSC-a zahtjevno je stoga što se tetiva retrahira i adherira medijalno u blizini neurovaskularnih struktura, a sam zahvat se odvija u relativno skučenom ekstraartikularnom prostoru. Tijekom operacije možemo doći u blizinu: nn. axillaris, musculocutaneus, subscapulares anterior et posterior, fasciculus lateralis plexus brachialis aa axillaris $\mathrm{i}$ circumflexa humeri posterior ${ }^{38}$. Prednosti artroskopskog operativnog liječenja su točno determiniranje uzorka i razmjera lezije, precizna adhezioliza, mobilizacija i rekonstrukcija, liječenje svih pratećih oštećenja te minimalna invazivnost zahvata. Opisano je i odsustvo masne degeneracije mišića nakon artroskopske u odnosu na otvorenu rekonstrukciju ${ }^{28}$. Na temelju artroskopske prezentacije postoji nekoliko klasifikacija lezije SSC-a, od kojih je u najširoj upotrebi ona po Lafosseu iz 2010. godine $28,39-41$ (tablica 1).

Artroskopsku rekonstrukciju možemo učiniti intraartikularno kod manjih lezija (Lafosse 1 - 2), ekstraartikularno, tj. burzalno kod većih (Lafosse 3 i više) ili pak njihovom kombinacijom ${ }^{41}$. Tijekom artroskopske operacije ruptura SSC-a prezentira se s nekoliko tipičnih znakova. Kod potpune retrahirane rupture gornjeg dijela tetive SSC-a dolazi do odvajanja medijalnog suspenzornog aparata CLMBB (engl. lig coracohumerale i lig glenohumerale superior) koji je u slučaju anterosuperiorne lezije spojen i s prednjem dijelom tetive SSP-a 
te se zbog specifične prezentacije naziva "comma sign"43. Pritom nalazimo i medijaliziranu tetivu CLMBB. Skrivene i manje lezije tetive SSC-a često prati parcijalna lezija tetive CLMBB koja se nalazi u kontaktu s lezijom SSC-a, a zovemo je "sentinel sign"44. Lezija tetive SSC-a u većini slučajeva uključuje leziju i/ili instabilitet tetive CLMBB te njena tenodeza ili tenotomija najčešće predstavlja sastavni dio operativnog liječenja ${ }^{45,46}$. Prilikom rekonstrukcije anterosuperiornih lezija "comma" tkivo se većinom ostavlja jer se na taj način olakšava repozicija i smanjuje tenzija na SSP, ali se može i odstraniti u sklopu adheziolize, što ovisi o odabiru kirurga ${ }^{47}$ (Slika 4).

U slučaju nemogućnosti anatomske repozicije tetive na njezino hvatište, tolerantna je medijalizacija od oko $7 \mathrm{~mm}$ bez komprotiranja funkcije $\mathrm{e}^{48}$. Kod nemogućnosti potpune rekonstrukcije masivnih lezija manžete, važno je pokušati parcijalnom rekonstrukcijom izbalansirati osovinu SSC - ISP / TM radi sprječavanja ili usporenja razvoja artropatije ${ }^{49,50}$. U slučaju masne degeneracije mišića i reponibilnosti tetive, rekonstrukciju ipak valja pokušati jer se može očekivati tenodezni efekt ${ }^{42}$. Adekvatna rekonstrukcija SSC-a neophodno je potrebna i u pripremi tetivno-mišićnog transfera kod nerekonstruktibilnih posterosuperiornih lezija te rekonstrukcije gornje čahure ramenog zgloba. U slučaju nerekonstruktibilnosti tetive SSC-a moguća je njena augmentacija i tetivno mišićni transfer ( $m$ pectoralis maior, $m$ latissimus dorsi, $m$ pectoralis minor). Kojoj vrsti

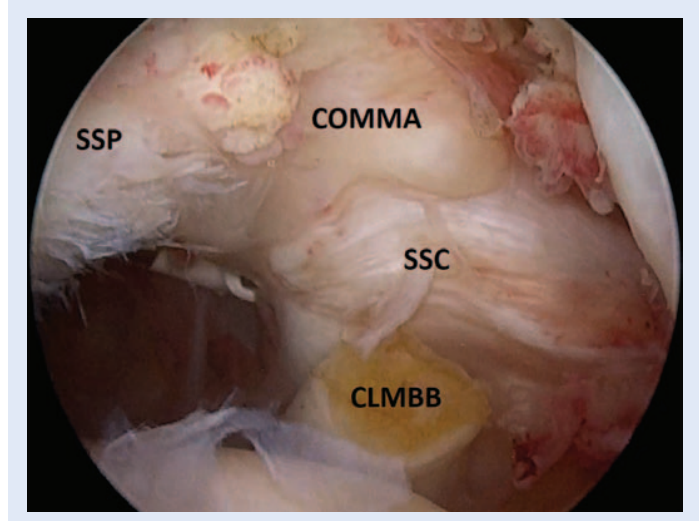

Slika 4. Intraartikularni prikaz anterosuperiorne lezije manžete uz potpunu rupturu gornje $2 / 3$ (Lafosse tip 3) tetive subskapularisa (SSC). Uočljivo je "COMMA" tkivo koje ga spaja sa supraspinatusom (SSP). Stanje po tenotomiji bicepsa (CLMBB) koji je medijaliziran. zahvata ćemo pristupiti ovisi o rekonstruktibilnosti tetive, dobi pacijenta, stupnju artropatije, stabilnosti ramena te stanju ostalih tetiva, a ponekad se kao najracionalniji potez nameće ugradnja inverzne proteze ramena ${ }^{42}$. Ovom studijom analiziramo isključivo artroskopske operacije oštećenja rotatorne manžete koje uključuju SSC.

\section{ISPITANICI I METODE}

U Klinici za ortopediju i traumatologiju Lovran u razdoblju od 1. siječnja 2015. do 1. siječnja 2019. učinili smo ukupno 289 artroskopskih ili artroskopski asistiranih operacija ramena radi oštećenja rotatorne manžete. Indikacije za operativni zahvat postavljene su na temelju anamneze, kliničkog pregleda, te dijelom ultrazvuka i/ili magnetske rezonancije, a lezija manžete potvrđena je na samom operativnom zahvatu. Operativni zahvati vršeni su u općoj hipotenzivnoj anesteziji uz skalenski blok. Položaj pacijenta na operacijskom stolu bio je polusjedeći, glava se nalazila u kacigi, a ruka koja se operirala u hidrauličnom držaču (Conmed) (Slika 5).

Od opreme koristili smo standardnu artroskopsku

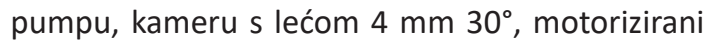
brijač, radiofrekventni uređaj te uobičajene instrumente za anterogradno i retrogradno artroskopsko šivanje različitih proizvođača. Tijekom zahvata koristili smo standardne portale: stražnji, prednji, anterolateralni i ponekad lateralni/posterolateralni, što je ovisilo o razmjerima oštećenja manžete (Slika 6).

Lezije SSC-a podijelili smo po Lafosseu ${ }^{28}$. Tetive smo rekonstruirali i za kost fiksirali titanskim ili končanim sidrima s po $2-3$ neresorptivna konca ili pak "knotless" sidrima različitih proizvođača u debljinama namijenjenim za rekonstrukciju manžete. Kao slobodan konac koristili smo Fiberwire Arthrex ili Orthocord Mitek br. 2. Kod lezija tetive SSC-a Lafosse 1 - 2 upotrijebili bismo 1 sidro, dok smo kod stupnja oštećenja Lafosse 3 i više koristili 2 i više sidara. Uz prateći instabilitet ili leziju tetive CLMBB vršili smo njenu tenodezu (artroskopsku suprapektoralnu ili minimalno otvorenu subpektoralnu) ili tenotomiju. Poslijeoperacijske protokole sastavljali smo individualno, koristili smo ortoze s operiranom rukom u blagoj fleksiji, abdukciji i unutrašnjoj rotaciji $4+2$ tjedna, uz pa- 


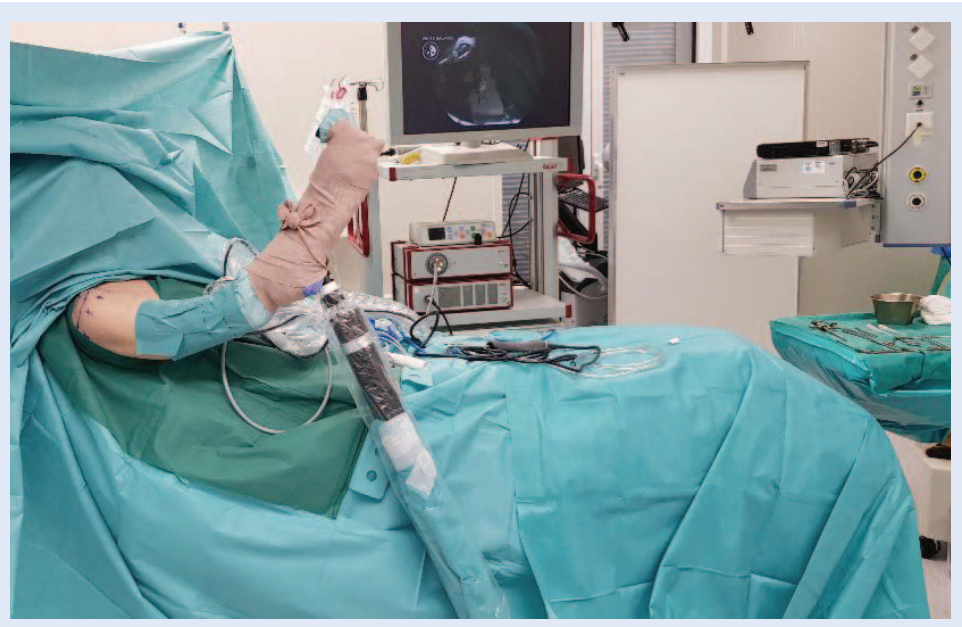

Slika 5. Polusjedeći položaj pacijenta na operacijskom stolu s rukom u hidrauličnom držaču.

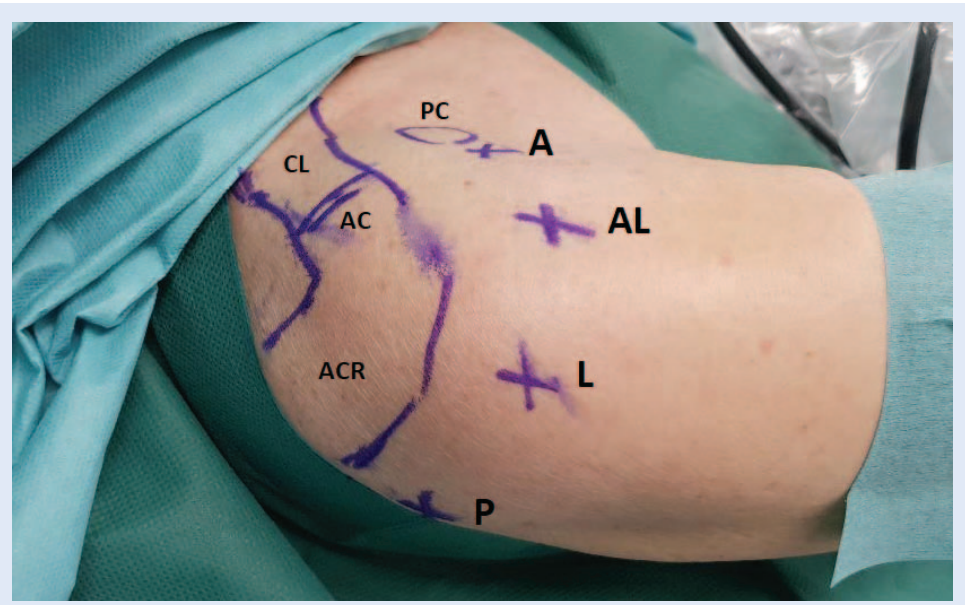

Slika 6. Standardni artroskopski portali i orijentacijske točke na ramenu: A (prednji portal), AL (anterolateralni portal), L (lateralni portal), P (stražnji portal), $\mathrm{PC}$ (processus coracoideus), $\mathrm{CL}$ (clavicula), AC (articulatio acromioclavicularis), ACR (acromion).

sivne i postepeno aktivne asistirane vježbe ramenom. Nakon 8 tjedana započinjali smo s aktivnim vježbama bez opterećenja, a s doziranim opterećenjem 3 mjeseca od operativnog zahvata. Analizirali smo rezultate artroskopskog liječenja 31 dostupnog pacijenta s lezijom tetive SSC-a kojima je od operacije do procjene prošlo 6 i više mjeseci. Pacijenti su ispitani o prije i poslijeoperacijskim mogućnostima i tegobama po upitniku Oxford shoulder score (OSS) i Subjective shoulder value (SSV) ${ }^{51,52}$.

\section{Statistika}

Statistička obrada podataka napravljena je uz pomoć računalnog programa Statistica verzija 13.3
(Tibco software Inc., USA). Za grafički prikaz podataka uz program Statistica korišten je i MS Office Excel. Deskriptivna statistika korištena je za opis kategorijskih podataka koji su iskazani postotcima. Kod usporedbe prije i poslijeoperacijskih vrijednosti OSS i SSV score najprije je ispitana normalnost podataka Kolmogorov-Smirnovljevim testom. Ove varijable koje se ne raspodjeljuju u skladu s normalnom raspodjelom prikazane su grafički uz medijan i interkvartilno raspršenje. Usporedbe vrijednosti prije i poslije operacije za OSS i SSV score učinjene su neparametrijskim testom za dva zavisna uzorka, tj. Wilcoxonovim testom ekvivalentnih parova. Kao razina statističke značajnosti u analizi primijenjeno je $p<0,05$.

\section{REZULTATI}

Od ukupno 289 operacija rotatorne manžete kod 89 slučajeva $(30,79 \%)$ našli smo oštećenje tetive SSC-a. U 8 pacijenata pronašli smo izoliranu leziju SSC-a (2,76 \% analiziranih lezija manžete), dok je kod 81 pacijenta lezija SSC-a bila udružena s oštećenjem ostalih tetiva rotatorne manžete. Kod 72 pacijenta s lezijom SSC-a $(80,9 \%)$ učinili smo potpuno artroskopsku operaciju, a u 17 slučajeva $(19,1 \%)$ otvorenu uz artroskopsku asistenciju. U $60 \%$ slučajeva našli smo parcijalnu intraartikularnu leziju SSC-a Lafosse 1, kod $20 \%$ potpunu leziju Lafosse 2, 17 \% Lafosse 3, 2 \% Lafosse 4 i 1 \% Lafosse $5^{28}$ (Slika 7).

Tijekom operativnog zahvata kod $40 \%$ pacijenata učinila se kompletna rekonstrukcija tetive, a kod $1 \%$ parcijalna. Kod $28 \%$ slučajeva ostavilo se oštećenje in situ, a u $26 \%$ učinio se samo debridement. U našem uzorku 5 \% lezija subskapularisa procijenjeno je nerekonstruktibilnim (Slika 8). Kod $73 \%$ pacijenata učinili smo tenotomiju (63\%) ili tenodezu (10\%) CLMBB, dok u $26 \%$ slučajeva tetivu CLMBB nismo dirali, što je isključivo ovisilo o intraoperativnoj procjeni stabilnosti i oštećenja tetive od strane operatera. Kod $1 \%$ pacijenata tetiva CLMBB je nedostajala zbog ranijeg puknuća. Nismo imali neurovaskularnih i infektivnih komplikacija. Dvoje pacijenata je reoperirano, pri čemu je nađena nerekonstruktibilna reruptura SSC-a, a pacijenti zbog godina starosti i razvoja artropatije predviđeni za ugradnju inverzne endoproteze. Kod dvoje pacijenata parcijalna rekon- 
strukcija masivne rupture manžete koja je uključivala potpunu rekonstrukciju SSC-a nije dala zadovoljavajući rezultat, stoga je u drugom aktu učinjen artroskopski asistirani transfer $m$. latissimusa dorsi zbog slabosti vanjskih rotatora (IS i TM). Uvjet za navedeni zahvat bio je klinički, dijagnostički i artroskopski dokaz uspješnosti rekonstrukcije SSC-a. Iz grupe artroskopski operiranih pacijenata, 31 dostupan procijenjen je nakon $17,96 \pm 8,25$ (aritmetička sredina \pm standardna devijacija) mjeseci od operacije s OSS i SSV upitnikom (odziv 43,05 \%). Starost pacijenata u doba operacije unutar ispitivane grupe je 59,52 \pm 6,73 godina. OSS se značajno povećao s 14,19 prijeoperativno, na 36,74 poslijeoperativno $(p=0,002)$ (Slika 9).

SSV se također značajno povećao s 27,32 na $82,33(p<0,001)$ (Slika 10).

\section{RASPRAVA}

Incidencija svih lezija SSC-a kod artroskopski liječenih oštećenja tetiva rotatorne manžete kroz 4 godine u Klinici za ortopediju i traumatologiju Lovran iznosila je 30,79\%. Ovaj postotak odgovara objavljenim rezultatima drugih autora kod kojih se incidencija lezija SSC-a kreće od $27,4 \%$ do $59 \%$ artroskopskih rekonstrukcija tetiva rotatorne manžete ${ }^{21-27}$. Incidencija izoliranih lezija SSC-a $\mathrm{u}$ istom uzorku iznosila je $2,76 \%$ te je nešto manja od u literaturi objavljenih rezultata drugih autora koji se kreću od $3 \%-5,3 \%$ svih artroskopski

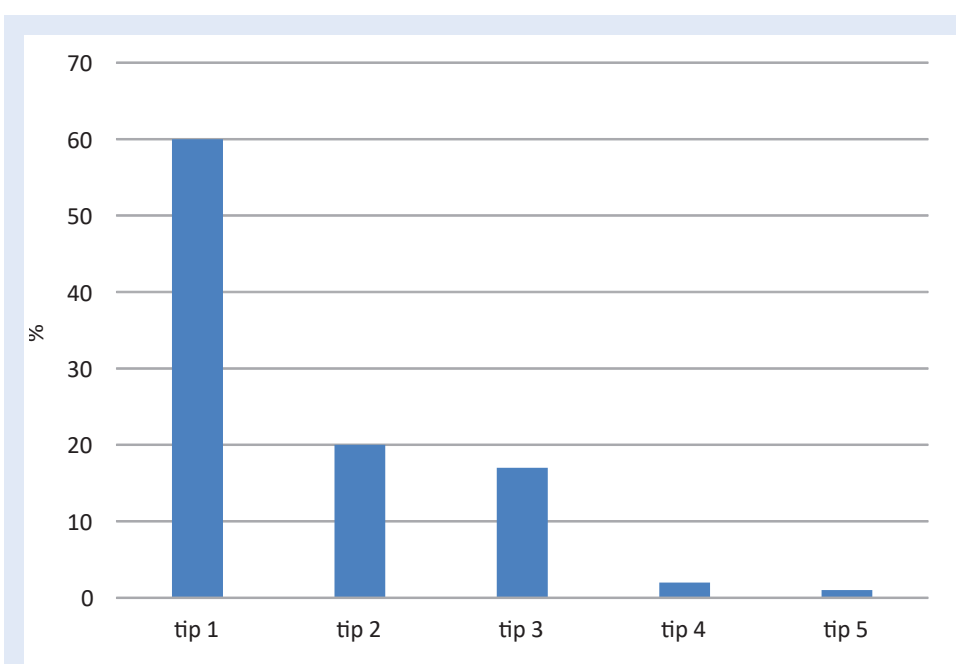

Slika 7. Lezije tetiva SSC-a u našem uzorku podijeljene po Lafosseu, izražene u postotcima.

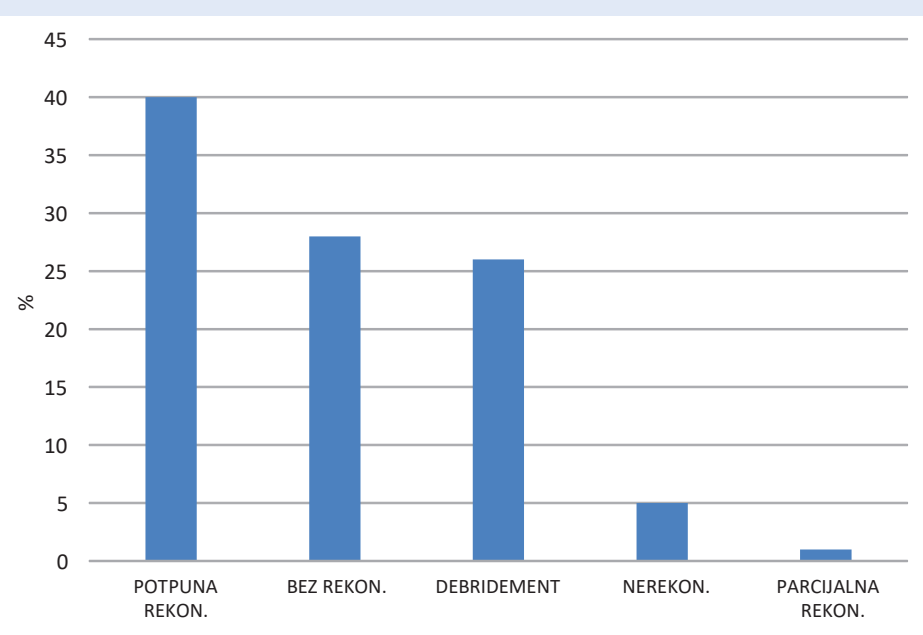

Slika 8. Načini operativnog liječenja lezija tetiva SSC-a u našem uzorku izraženi u postotcima.

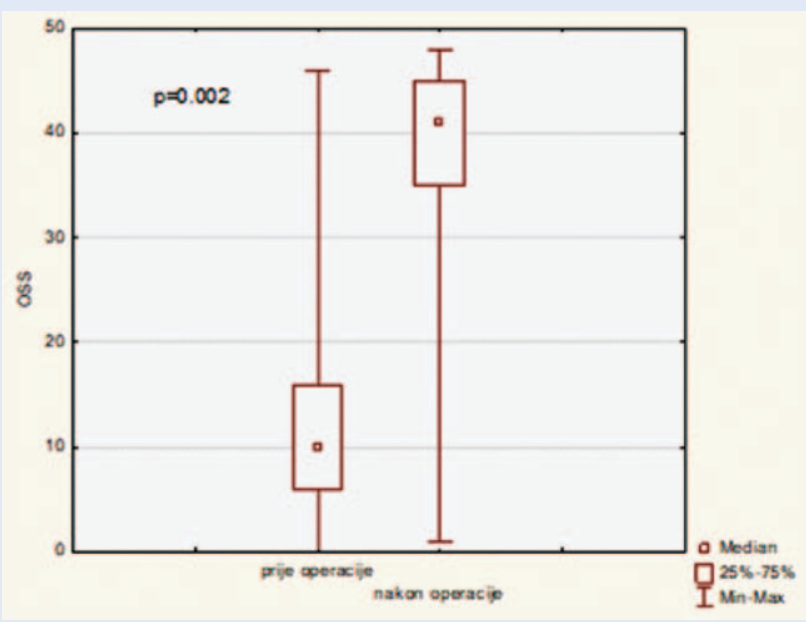

Slika 9. Oxford shoulder score (OSS): Grafički prikaz razlike uz medijan i interkvartilno raspršenje.

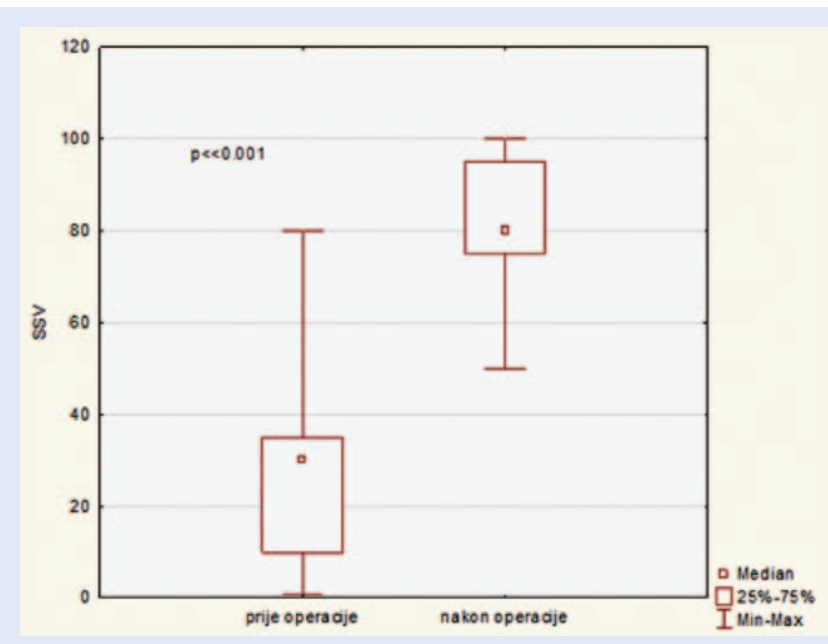

Slika 10. Subjective shoulder value (SSV): Grafički prikaz razlike uz medijan i intarkvartilno raspršenje. 
liječenih lezija rotatorne manžete ${ }^{27-32}$. Razloge manje incidencije izoliranih lezija SSC-a u našem uzorku valjalo bi istražiti dodatnim analizama. Većinu (60\%) oštećenja SSC-a kod naših pacijenata činile su parcijalne intraartikularne lezije (Lafosse gr 1) kod kojih smo ovisno o procjeni operatera činili debridement nestabilnih dijelova tetive, njenu rekonstrukciju preko 1 sidra ili pak ostavili leziju nedirnutu (in situ) u slučaju manjeg oštećenja. U slučaju prateće lezije ili suspektnog instabiliteta tetive CLMBB činili smo njenu tenotomiju ili subpektoralnu/suprapektoralnu tenodezu. Čimbenici kojima smo se povodili $u$ donošenju odluke o načinu njenog tretiranja bili su starost, aktivnost, opće zdravstveno stanje te konstitucija pacijenta, kao i razmjeri oštećenja tetive CLMBB. Potpunu leziju gornje 1/3 (Lafosse 2) tetive SSC-a našli smo u $20 \%$ slučajeva. Takve lezije tipično se ne retrahiraju previše, te je rekonstrukcija nakon repozicije i fiksacije tetive preko jednog sidra u pravilu bila kompletna. Potpunu leziju gornje 2/3 (Lafosse 3) našli smo kod $17 \%$, dok leziju cijele visine tetive SSC-a (Lafosse 4) kod $2 \%$ naših pacijenata. Takve lezije često je pratila izraženija medijalna retrakcija uz adheriranje za okolne strukture, bila je potrebna pomna i pažljiva adhezioliza, a repozicija i rekonstrukcija nisu uvijek u potpunosti bile moguće. Tetivu smo fiksirali na hvatište ili njegovu blizinu uz tolerantnu medijalizaciju s $2 \mathrm{i}$ više sidara ${ }^{42,48}$. Potpunu leziju cijele visine tetive SSC-a uz značajniju masnu atrofiju mišića (Goutallier $3-4$ ) i subluksaciju glave humerusa (Lafosse 5) našli smo kod 1 pacijenta, učinili smo dijagnostičku artroskopiju i toaletu te indicirali ugradnju inverzne proteze ramena. Kod $60 \%$ pacijenata SSC smo potpuno rekonstruirali, kod $1 \%$ pacijenata parcijalno, a $5 \%$ lezija bilo je nerekonstruktibilno. Potpune lezije SSC-a najčešće zahtijevaju tenodezu ili tenotomiju CLMB-a, što smo u ovim slučajevima i činili. U provjeri rezultata naših artroskopskih rekonstrukcija koristili smo OSS i SSV upitnike bazirane na subjektivnoj procjeni funkcionalnosti i tegoba s ramenom od strane samih pacijenata. Oba testa pokazala su statistički značajnu razliku između prijeoperacijskih i poslijeoperacijskih vrijednosti, što se podudara s rezultatima ostalih studija koje su analizirale rezultate artroskopskih rekonstrukci- ja lezija tetiva SSC-a ${ }^{51}$. OSS i SSV u objavljenim radovima donekle mogu korelirati s rezultatima testova koji se baziraju na objektivnoj liječničkoj procjeni i pregledu ${ }^{52,53}$. Subjektivnost pacijenata u procjeni svog stanja moguća je mana ovakve provjere, uz izrazitu prednost jednostavnog i brzog provođenja.

\section{ZAKLJUČCI}

Unatoč svoje zahtjevnosti, artroskopsko liječenje oštećenja tetive SSC-a nakon adekvatne pripreme i savladavanja krivulje učenja predstavlja siguran $\mathrm{i}$ efikasan način liječenja koje po našem iskustvu daje odlične rezultate bez izraženijih komplikacija. Stava smo da preciznost koju omogućuje artroskopski zahvat uz sve dobro poznate prednosti minimalno invazivne kirurgije daju prednost artroskopskoj u odnosu na otvorenu rekonstrukciju lezija SSC-a.

Izjava o sukobu interesa: Autori izjavljuju da ne postoji sukob interesa

\section{LITERATURA}

1. Keating JF, Waterworth P, Shaw-Dunn J, Crossan J. The relative strengths of the rotator cuff muscles. A cadaver study. J Bone Joint Surg Br 1993;75:137-140.

2. Smith JG. Pathological appearance of seven cases of injury of the shoulder joint, with remarks. London Med Gaz 1834;14:280-285.

3. Codman EA. The shoulder: rupture of the supraspinatus tendon and other lesions in or about the subacromial bursa. Boston: Thomas Todd Co, 1934.

4. McLaughlin HL. Lesions of the musculotendinous cuff of the shoulder: I. The exposure and treatment of tears with retraction. J Bone Joint Surg Am 1944;26:31-51.

5. McLaughlin HL. Recurrent anterior dislocation of the shoulder. Am J Surg 1960;99:628-632.

6. Hauser ED. Avulsion of the tendon of the subscapularis muscle. J Bone Joint Surg Am 1954;36:139-141.

7. Gerber C, Krushell RJ. Isolated rupture of the tendon of the subscapularis muscle: Clinical features in 16 cases. J Bone Joint Surg Br 1991;72:389-394.

8. Lo IK, Burkhart SS. Subscapularis tears: Arthroscopic repair of the forgotten rotator cuff tendon. Techniques in Shoulder and Elbow Surgery 2002;3:282-291.

9. Burkhart SS, Tehrany AM. Arthroscopic subscapularis tendon repair: technique and preliminary results. Arthroscopy 2002;18:454-463.

10. Ide J, Tokiyoshi A, Hirose J, Mizuta H. An Anatomic Study of the Subscapularis Insertion to the Humerus: The Subscapularis Footprint. Arthroscopy 2008;24:749-753.

11. Kasper JC, Itamura JM, Tibone JE, Levin SL, Stevanovic MV. Human cadaveric study of subscapularis muscle innervation and guidelines to prevent denervation. Shoulder Elbow Surg 2008;17:659-662. 
12. Habermeyer P, Magosch P, Pritsch M, Scheibel MT, Lichtenberg S. Anterosuperior impingement of the shoulder as a result of pulley lesions: a prospective arthroscopic study. J Shoulder Elbow Surg 2004;13:5-12.

13. Inman VT, Saunders JB, Abbott LC. Observations of the function of the shoulder joint. 1944. Clin Orthop Relat Res 1996;330:3-12.

14. Parsons IM, Apreleva M, Fu FH, Woo SL. The effect of rotator cuff tears on reaction forces at the glenohumeral joint. J Orthop Res 2002;20:439-446.

15. Burkhart SS. Arthroscopic treatment of massive rotator cuff tears. Clinical results and biomechanical rationale. Clin Orthop Relat Res 1991;267:45-56.

16. Neer CS 2nd, Craig EV, Fukuda H. Cuff-tear arthropathy. J Bone Joint Surg Am 1983;65:1232-44.

17. Reuther KE, Thomas SJ, Tucker JJ, Sarver JJ, Gray CF, Rooney $\mathrm{SI}$ et al. Disruption of the Anterior-Posterior Rotator Cuff Force Balance Alters Joint Function and Leads to Joint Damage in a Rat Model. J Orthop Res 2014;32: 638-644.

18. Collin P, Matsumura N, Lädermann A, Denard PJ, Walch G. Relationship between massive chronic rotator cuff tear pattern and loss of active shoulder range of motion. J Shoulder Elbow Surg 2014;23:1195-202.

19. Kuechle DK, Newman SR, Itoi E, Morrey BF, An KN. Shoulder muscle moment arms during horizontal flexion and elevation. J Shoulder Elbow Surg 1997;6:429-39.

20. Warner JP, Higgins L, Parsons IV IM, Dowdy P. Diagnosis and treatment of anterosuperior rotator cuff tears. J Shoulder Elbow Surg 2001;10:37-46.

21. Pandey V, Jaap Willems W. Rotator cuff tear: A detailed update. Asia Pac J Sports Med Arthrosc Rehabil Technol 2015;2:1-14.

22. Edwards TB, Walch G, Sirveaux F, Molé D, NovéJosserand L, Boulahia A et al. Repair of tears of the subscapularis: surgical technique. J Bone Joint Surg Am 2006;88:1-10.

23. Bennett WF. Subscapularis, medial, and lateral head coracohumeral ligament insertion anatomy: arthroscopic appearance and incidence of "hidden" rotator interval lesions. Arthroscopy 2001;17:173-80.

24. Arai R, Sugaya H, Mochizuki T, Nimura A, Moriishi J, Akita K. Subscapularis tendon tear: an anatomic and clinical investigation. Arthroscopy 2008;24:997-1004.

25. Bennett WF. Arthroscopic repair of isolated subscapularis tears: a prospective cohort with 2- to 4-year followup. Arthroscopy 2003;19:131-43.

26. Barth JR, Burkhart SS, De Beer JF. The bear-hug test: a new and sensitive test for diagnosing a subscapularis tear. Arthroscopy 2006;22:1076-84.

27. Lafosse L, Jost B, Reiland Y, Audebert S, Toussaint B, Gobezie R. Structural integrity and clinical outcomes after arthroscopic repair of isolated subscapularis tears. J Bone Joint Surg Am 2007;89:1184-1193.

28. Lafosse L, Lanz U, Saintmard B, Campens C. Arthroscopic repair of subscapularis tear: Surgical technique and results. Orthop Traumatol Surg Res 2010;96:S99-108.

29. Nove-Josserand L, Hardy MB, Ogassawara RLN, Carrillon $Y$, Godeneche A. Clinical and structural results of arthroscopic repair of isolated subscapularis tear. J Bone Joint Surg Am 2012;94:e125.

30. Heikenfeld R, Gigis I, Chytas A, Listringhaus R, Godolias G. Arthroscopic reconstruction of isolated subscapularis tears: Clinical results and structural integrity after 24 months. Arthroscopy 2012;28:1805-1811.

31. Naimark $M$, Zhang AL, Leon I, Trivellas A, Feeley $B T, M a$ CB. Clinical, radiographic, and surgical presentation of subscapularis tendon tears: A retrospective analysis of 139 patients. Arthroscopy 2016;32:747-752

32. Flury $M$, John M, Goldhahn J, Schwyzer H, Simmen B. Rupture of the subscapularis tendon (isolated or in combination with supraspinatus tear): when is a repair indicated? J Shoulder Elbow Surg 2006;15:659-64.

33. Gerber C, Hersche O, Farron O. Isolated rupture of the subscapularis tendon: results of operative repair. J Bone Joint Surg Am 1996;78:1015-1023.

34. Barth JR, Burkhart SS, De Beer JF. The bear-hug test: a new and sensitive test for diagnosing a subscapularis tear. Arthroscopy 2002;22:1076-84.

35. Gerber C, Krushell RJ. Isolated rupture of the tendon of the subscapularis muscle: Clinical features in 16 cases. J Bone Joint Surg Br 1991;72:389-394.

36. Fuchs B, Weishaupt D, Zanetti M, Hodler J, Gerber C. Fatty degeneration of the muscles of the rotator cuff: assessment by computed tomography versus magnetic resonance imaging. J Shoulder Elbow Surg 1999;8:599605.

37. Goutallier D, Postel JM, Bernageau J, Lavau L, Voisin MC. Fatty muscle degeneration in cuff ruptures: pre- and postoperative evaluation by CT scan. Clin Orthop Relat Res. 1994;304:78-83.

38. Lo IK, Burkhart SS, Parten PM. Surgery About the Coracoid: Neurovascular Structures at Risk. Arthroscopy 2004;20:591-5.

39. Yoo JC, Rhee YG, Shin SJ, Park YB, McGarry MH, Jun BJ et al. Subscapularis tendon tear classification based on 3-dimensional anatomic footprint: a cadaveric and prospective clinical observational study. Arthroscopy 2015;31:19-28.

40. Pfirrmann CW, Zanetti M,Weishaupt D, Gerber C, Hodler J. Subscapularis tendon tears: detection and grading at MR arthrography. Radiology 1999;213:709-14.

41. Toussaint B, Barth J, Charousset C, Godeneche A, Joudet T, Lefebvre $Y$ et al. New endoscopic classification for subscapularis lesions. Orthop Traumatol Surg Res 2012 Dec;98:S186-92

42. Lee J, Shukla DR, Sánchez-Sotelo J. Subscapularis tears: hidden and forgotten no more. JSES Open Access 2018;2:74-83.

43. Lo IK, Burkhart SS. The comma sign: An arthroscopic guide to the torn subscapularis tendon. Arthroscopy 2003;19:334-7.

44. Sahu D, Fullick R, Giannakos A, Lafosse L. Sentinel sign: a sign of biceps tendon which indicates the presence of subscapularis tendon rupture. Knee Surg Sports Traumatol Arthrosc 2016;24:3745-3749.

45. Godenèche $A$, Nové-Josserand L, Audebert $S$, Toussaint B, Denard PJ, Lädermann A. Relationship between subscapularis tears and injuries to the biceps pulley. Knee Surg Sports Traumatol Arthrosc 2017;25:2114-2120.

46. Denard PJ, Lädermann A, Burkhart SS. Arthroscopic management of subscapularis tears. Sports Med Arthrosc Rev 2011;19:333-41.

47. Kim SJ, Jung M, Lee JH, Kim C, Chun YM. Arthroscopic repair of anterosuperior rotator cuff tears: in-continuity technique vs. disruption of subscapularis-supraspinatus tear margin: comparison of clinical outcomes and struc- 
tural integrity between the two techniques. J Bone Joint Surg Am 2014;96:2056-61.

48. Denard PJ, Burkhart SS. Medialization of the subscapularis footprint does not affect functional outcome of arthroscopic repair. Arthroscopy 2012;28:1608-14.

49. Burkhart SS. Partial repair of massive rotator cuff tears: the evolution of a concept. Orthop Clin North Am 1997; 28:125-132.

50. Burkhart SS. A stepwise approach to arthroscopic rotator cuff repair based on biomechanical principles. Arthroscopy 2000;16:82-90.
51. Lenart BA, Ticker JB. Subscapularis tendon tears. Management and arthroscopic repair. EFORT Open Rev 2017;2:484-495.

52. Cloke DJ, Lynn SE, Watson H, Steen IN, Purdy S, Williams $J R$. A comparison of functional, patient-based scores in subacromial impingement. J Shoulder Elbow Surg 2005; 14:380-4.

53. Gilbart MK, Gerber C. Comparison of the subjective shoulder value and the Constant score. J Shoulder Elbow Surg 2007;16:717-21. 